\title{
MOTOR FEATURES, DERMATOGLYPHIC AND EEG PERIODS OF GIRLS IN PRE AND POST MENARCHE
}

\author{
Letícia Ecard Rocha ${ }^{1,2,3}$, Paula Roquetti Fernandes ${ }^{1,2}$, and José Fernandes Filho ${ }^{1,4}$ \\ ${ }^{1}$ Centre of Excellence in Physical Evaluation - CEAF, Rio de Janeiro - Brazil \\ ${ }^{2}$ Biosciences Laboratory of Human Movement - LABIMH - UFRJ, Rio de Janeiro - Brazil \\ ${ }^{3}$ Universidad Autónoma de Asunción - UAA - PY, Asunción, Paraguay \\ ${ }^{4}$ University Federal of Rio de Janeiro -UFRJ, Rio de Janeiro - Brazil
}

\section{SUMMARY}

The identification of menarche at puberty is important to evaluate the physical qualities, since the organism is developing a result of maturation. The dermatoglyphic characteristics are presented as possible indicators of genetic predispositions for basic physical qualities such as strength, speed, endurance, power and coordination. The aim of this study is relation of motor characteristics, dermatoglyphic and brain electro in girls in the periods before and after menarche. For this purpose the sample consisted of 45 girls aged between 10 and 14 years and 11 months divided into two groups, 21 in pre-menarche group (G1) and 24 in post menarche (G2). The variables analyzed were: motor characteristics, dermatoglyphic and EEG (absolute power in alpha and beta) electrodes in the frontal regions $(\mathrm{F})$, central $(\mathrm{C})$ and parietal $(\mathrm{P})$, using the protocol KTK, protocol and capture fingerprints spectral activity through EEG. The results show a significant difference in QM4 for a $p \leq .05$ between groups G1 and G2, and the G2 achieved better performance. Compared the results of the motor characteristics, dermatoglyphic and electroencephalographic they indicate significant differences in spectral activity of the alpha rhythm in girls belonging to the group after menarche. It was observed that, with respect to motor characteristics, dermatoglyphic and EEG, the groups are not presented separately. However, to join the motor characteristics, dermatoglyphic and EEG groups before and after menarche, there was a significant difference with respect to brain activity only in the alpha rhythm and at frontal (F3, FZ, F4) and central (C3 and CZ) and in the post menarche.

Key Words: menarche, coordination, dermatoglyphics, electroencephalography.

\section{INTRODUCTION}

Puberty is a stage of human life characterized by various transformations both physical and psychosocial. At this stage, the assessment of sexual maturation becomes an important parameter to assess whether the influences that it exerts on the growth and development, whereby a maturational diversity can be found among individuals with the same chronological age (Fonseca Júnior, Dantas, \& Fernandes Filho, 2009). The stage of growth and maturation is regulated by the anterior pituitary gland located at the base of the brain, into the cell turcica of the sphenoid bone. Some hormones from the anterior pituitary, including so- matropin, corticotropin, thyrotropin, gonadotropin and prolactin have an important role during the growth and maturation of human being (Malina, Bouchard, \& Bar-Or, 2009).

Being the body, motility wise, the place of the sense and possible (Sérgio, 2001) the presence of menarche is a significant event in a woman's life and involves transformations in her own body of order somatic, metabolic and neuromotor transformations. Related to neuromotor transformations, Collet, Folle, Pelozin, Botti, and Nascimento (2008) corroborates these ideas saying that in recent years the motor coordination has been investigated because of the growing importance of the psychomotor domain 
related to the autonomy of the human being, especially during periods of growth and maturation. Motor coordination is essential to perform some basic skills and can be enhanced during motor learning throughout life (Schimidt \& Wrisberg, 2006).

According to Eckert (1993) one of the changes that occur in females in the beginning of menarche is related to changes in anthropometric, going on an increase in body weight and height and consequently the increase of body mass index (BMI) of adolescents. This increase in body mass, as well as being linked to sexual maturation, may also be associated with sedentary behavior that affects teenagers (Mendonça \& Anjos, 2004). Studies have been developed in order to investigate the influence of high body mass indexes on aspects that concern the manifestation of chronic diseases in adulthood (Oliveira, Cerqueira, Souza, \& Oliveira, 2003).

The lack of motor coordination relates to a general motor instability, involving problems in conducting the movement triggered by an incorrect action of the functional structures, sensory nerve and muscle, which consequently leads to changes in the quality of movement and reduction of motor efficiency (Silva, 2007). In order to achieve better performance and minimize such shortcomings, it is necessary to study the genetic potential of each athlete, thus obtaining an improvement of sports preparation and guidance about its features pre-disposition to certain tasks, since studies show the existence of a relationship between dermatoglyphic patterns, the physical qualities and also the types of muscle fibers. Fernandes Filho (1997) reports that, based on the model of fingerprints, facilitates the choice of the appropriate sport or even the function of players on the field, court or appropriate expertise to existing genetic characteristics, and thus contributes to the reduction of dropouts and same frustrations coming from the choice of sport or activity poorly suited to the capabilities of each individual.

In terms of maturity, capturing brain activity is also important in this age group, since it is characterized by changes in brain electrical activity (Gasser, Verleger, Bãcher, \& Sroka, 1988). With increasing age, the background activity of the EEG undergoes modifications, particularly for infants, pre-school age, but still variations to the end of adolescence (Eckert, 1993).

Grounded in such arguments and in the face of a greater contribution of work in the area of Physical Education that will focus the menarche and its relationship to motor coordination, dermatoglyphic and electroencephalography, the present study aimed to verify and relate, the motor, dermatoglyphic and electroencephalographic characteristics of girls in the pre-and post-menarche.

\section{METHODS}

The study was methodologically developed along the lines of an investigative research, descriptive, comparative and associative (Thomas, Nelson, \& Silverman, 2007). Participants were, intentionally, 48 (forty eight) girls, 24 in the pre-menarche, with the loss of 3 of these girls during the collection process, then getting the pre menarche group consisted of 21 girls, and 24 post-menarche, students of the Integrated Center for Public Education (CIEP) 275 - city of Itaocara/RJ, whose ages ranged from 10 to 15 years old. To be part of the study involved should be within the age group between 10 and 15 years old, have answered the questionnaire of sexual maturation to identify the presence or absence of menarche and authorized by their parents and/or guardians through informed consent for participation and free consent. Were excluded from the sample girls who refused to participate as volunteers, to submit any physical deficiencies that could possibly impede the execution of motor tests and who did not attend on the appointed days for test execution.

The study was conducted in accordance with the rules for conducting research on human beings, Resolution 196/96 of the National Health Council, October 10, 1996. (CNS, 1996) being subjected to analysis by the Ethics Committee of the Universidad Autónoma de Asunción - UAA and approved under number 09/10 dated 20 August 2010.

\section{Experimental procedure}

After application of questionnaire (Oliveira Junior, 1996) for identifying the presence and/or absence of menarche, the evaluated were divided into two groups: pre-menarche (G1) and after menarche (G2). For the tests of motor coordination, collection of fingerprints (dermatoglyphic) and capture the EEG signal was used, respectively, the KTK test (Kiphard \& Schilling, 1974) battery consisting of four motor tasks, having components as balance, rhythm, laterality, speed, agility and has an individual reliability between $65-87 \%$ and a total of $90 \%$ reliability which demonstrates credibility to the application of this test; a fingerprint collector, following the protocol and Roquetti Fernandes and Fernandes Filho (2010) and appliance pickup EEG and international 10-20 system (Jasper, 1958). 


\section{Protocols}

Motor characteristics (Gorla, Duarte, \& Montagner, 2009):

- Task 01 - Motor Quotient 1 (QM1) - Balanced backpedal (ER) - sed three balance beams of three meters in length and $3 \mathrm{~cm}$ in height, with widths of $6 \mathrm{~cm}, 4.5 \mathrm{~cm}$ and $3 \mathrm{~cm}$. At the bottom of these balance beams are rafters measuring $15 \times 1.5 \times 5 \mathrm{~cm}$, and spaced $50 \mathrm{~cm}$ each one, making the balance beams reach a total height of $5 \mathrm{~cm}$. The task consisted in backpedaling on the three balanced beams, with different thicknesses, which were placed parallel 1 meter away from each other. Three valid attempts are recorded, making a total of nine attempts. The number of steps until one of the feet touch the ground or be achieved 8 points (steps) should be counted. For exercise and balance beam, the maximum that can be achieved are 8 points. The maximum possible score is 72 points. After nine attempts, adds to the value of the numbers of backpedals and get the result.

- Task 02 - Motor Quotient 2 (QM2) - Single Leg Vertical Jump (SM): was used 12 foam blocks each having $50 \times 20 \times 5 \mathrm{~cm}$, the task was to jump three times with his right leg and three times in the left leg with increasing altitude. To skip the blocks of foam, the individual needed a distance of $1.50 \mathrm{~m}$ to drive, which should also be exceeded in jumps with the same leg. After skipping the foam block, the individual needed to take at least two more jumps with the same leg, so that the task was completed. For each height, the performances were analyzed as follows: $1^{\text {st }}=3$ points valid attempt, $2^{\text {nd }}=2$ points and $3^{\text {rd }}=1$ point. The heights recommended for initiating the test in years, are: 5 to $6=$ no foam pad; $6-7$ years $=5 \mathrm{~cm}$ (one block of foam); 7-8 years $=$ $15 \mathrm{~cm}$ (three foam blocks); 9 to 10 years $=25 \mathrm{~cm}$ (five blocks of foam) and from 11 to 14 years and 11 months $=35 \mathrm{~cm}$ (seven foam blocks).

- Task 03 - Motor Quotient 3 (QM3) - lateral jumps (SL): with the use of an adhesive tape was marked on the ground a rectangle measuring $60 \times 50 \mathrm{~cm}$. With a $60 \times 4 \times 2 \mathrm{~cm}$ wooden slats was made to divide this rectangle so that the task of jumping with legs together from side to side after a whistle was held in $15 \mathrm{~s}$. Was recorded, in the number of Hops, two passes and the result obtained with the sum of them.

- Task 04 - Motor Quotient 4 (QM4) - Transposition Lateral (TL): were deposited on the ground, away from each other to $5 \mathrm{~cm}$, two wooden

\section{FIGURE 1}

The types of drawings of fingerprints: Arch (A), Hook (L), Whorl (W)

(Source: Roquetti Fernandes, 2004).

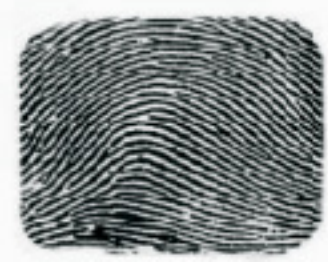

$\operatorname{Arch}(\mathrm{A})$

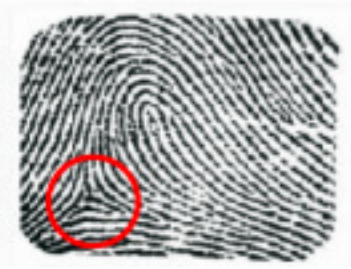

Hook (L)

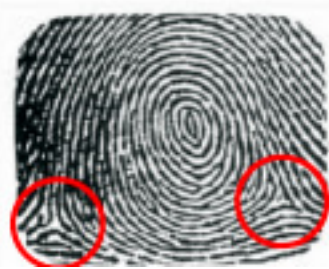

Whorl (W) platforms containing bases and measuring 25 x $25 \mathrm{~cm}$. Was asked to evaluate whether a position itself on one of them, and at the sound of a whistle, should move to another. Then it should take the platform from which it emerged and allocate it sideways. These movements should be performed two times or repeated as many times as possible in 20s. Have been computed the both of the number of transference platforms $=1$ point, as the body $=2$ points. After the execution of two attempts, the result was obtained with the sum of points both attempts.

\section{Dermatoglyphic features:}

Regarding collection of prints of ten fingers we used a digital collector's mark Cross Match ${ }^{\circledR}$, Verifier 320 LC $^{\circledR}$ and acquisition software BioUnistation Biology ${ }^{\circledR}$. It was treated of a collection whose procedure was: after the hands are clean, the appraised supported the first finger to be collected starting from the position ulnar and rotating in her longitudinal axis in the radial sense. Had to be careful not to overlap the finger on the scanner again. The procedure was repeated with each of the fingers, beginning and ending at a minimum by the thumb of both hands (Roquetti Fernandes, 2004). 
After obtaining the fingerprints, there was the reading of the same following the pattern below:

- Arc "A" - with no deltas drawing - is characterized by the absence of trirrádios or deltas and is composed of ridges crossing transversely the digital pad.

- Catch " $L$ " - has a delta. This is a drawing enclosed in which the ridges of the skin begin to curl up from one end of the finger distally relative to each other, but without approaching that where they start.

- Whorl "W" - designs of two-deltas. A closed figure, in which the center lines are concentrated around one or more core in the drawing. Below are shown the types of drawings of fingerprints (Figure 1).

Features electroencephalographic (EEG):

For the EEG signal capture device was used Braintech 3000 (EMSA - Medical Instruments, Brazil) system that uses a digital-analog converter board (A/D) of 32 channels with 12 bit resolution. EEG signals were filtered analog between $16 \mathrm{~Hz}$ (high-pass) and $35 \mathrm{~Hz}$ (low-pass) with a sampling rate of $200 \mathrm{~Hz}$ was used EEG acquisition software called Capture (Emsa-DELPHI 5.0). The international system 10-20 (Jasper, 1958) was used for placement of 19 unipolar electrodes over the scalp (areas: frontal, temporal, parietal and occipital) and an electrode in each ear (lobe), and used as references (bi-atrial). We checked a priori impedance levels for each electrode, whose values were maintained between 5-10 K $\Omega$ (Kilo-ohms). For the acquired signals have full amplitude (peak to peak) less than $100 \mu \mathrm{V}$, it was amplified with a gain of approximately 20.000 times.

Involved them in the study were submitted to the reception of the sign EEG uptake at rest. The data collected relate only to absolute power (PA) of beta rhythms $(13-35 \mathrm{~Hz})$ and alpha $(8-12 \mathrm{~Hz})$, since alpha is the individual lying down and relaxed wakefulness with eyes closed, and beta be associated with processes of sensory-motor integration. Only electrodes located in frontal areas (F3-F4), central (C3-C4) and parietal (P3-P4) were selected. Frontal areas were analyzed because of their association with mechanisms of attention, motivation and planning. Central and parietal electrodes were analyzed as representative areas of pre motor and primary motor, and primary sensory (Goda \& Stevens, 1996) somatosensory areas.

The room used for the test was prepared with a sound isolation and during the examination, the lights were kept to a maximum. The subjects sat comfortably in a chair with a slight slope, with their arms supported, with the aim of reducing muscular artifacts.
After collection of data and its associated archive was used to calculate the dependent variable extracted from quantitative electroencephalography (qEEG). A routine in Matlab 5.3 ${ }^{\circledR}$ (Mathworks Inc., Naticj, Ma, USA) was implemented to perform spectral analysis and estimate the specific parameter of interest: absolute power in the alpha and beta rhythms.

\section{Statistical treatment}

Descriptive statistics: The descriptive analysis presented consisted of a set of measures aimed to define the profile of each group studied, obtaining representative values of the data obtained through the measures of central tendency (mean), and characterizing the variation of these data, by means of measures of dispersion (standard deviation) and for percentiles.

Inferential statistics: Tests were used KomolgorovSmirnov and Shapiro-Wilk test and QQ Plot order to obtain a distribution curve of the data. From these results, it was found that the data is not normally distributed. So, to compare the data we used bivariate nonparametric Mann-Whitney test, and $p \leq .05$.

In the case of an experiment with several variables, we chose to examine, in the light of the multivariate analysis of Cluster, if there was a single association or set of associations between variables. For this purpose, we used the age factor for the creation of cases: the case $1=10$ years; case $2=15$ years and case $3=12$ years; choosing the number of three (3) cases is intended to reduce clusters. The significance level of $5 \%$ was considered, which defines as a rule of decision when the results present $p<.05$ can be stated that for the variable being tested, there is a significant difference.

\section{RESULTS AND DISCUSSION}

Results are presented and then, with basement discussed in the literature searches in order to provide a better understanding of relevant data.

\section{Results comparing motor characteristics, dermatoglyphic and EEG between $\mathrm{G} 1$ and $\mathrm{G} 2$}

Comparing the performance of pre-menarche girls (G1) and post-menarche (G2) (Table 1), it was observed that there was no significant difference to a value of $p \leq .05$ in the performance of tasks related to (QM1) (QM2) and (QM3). However, in the last task that makes up the protocol used, and refers to (QM4), it was found a significant difference to a value of $p \leq .05$ between groups $\mathrm{G} 1$ and G2, with the best performance achieved G2. 


\section{TABLE 1}

Comparison of the results of motor characteristics between groups G1 and G2.

\begin{tabular}{crrrr}
\hline \multicolumn{5}{c}{$M$} \\
\hline & QM1 & QM2 & QM3 & QM4 \\
\hline G1 & 26.64 & 25.72 & 20.24 & 27.67 \\
\hline G2 & 19.81 & 20.79 & 25.42 & 18.92 \\
\hline$p$ & .267 & .118 & .090 & $\mathbf{. 0 5 0}$ \\
\hline
\end{tabular}

Legend: QM1 - Balanced backpedal; QM2 - Single Leg Vertical Jump; QM3 - Lateral jumps;

QM4 - Transposition Lateral; $M$ - Mean; G1 - Group 1; G2 - Group 2;

$p$ - Probability.

Knowing that the motor performance during childhood and adolescence has a strong association with the processes of growth and maturation, Malina, Bouchard, and Bar-Or (2009) discuss several factors that influence the performance, such as maturation and cultural factors, body size and other. Thus, the growth and maturation are considered interrelated processes influenced by media interdependent and interrelated. Thus Mirwald, Baxter-Jones, Bailey, and Beunen (2002) discuss that the evaluation of maturity when related to adolescents is of great importance for effective motor program. The physical exercise during the stages of childhood and adolescence can aid in the overall development of individuals in maintaining body weight and improved levels of coordination (Collet, Folle, Pelozin, Botti, \& Nascimento, 2008).

Linhares et al. (2009) emphasize that, as a phase of constant and large changes, puberty and its variables ask the professionals who work directly with the people who are in this stage, detailed knowledge in relation to growth and development in order facilitate and provide a crucial motor work, avoiding excesses in relation to the stage where your teen is. Thus Vidal et al. (2009) indicate the battery of tests KTK as a user-friendly tool to assess the coordination of the participants. However, Gorla, Duarte, and Montagner (2008) describe that the KTK test battery should not be seen as just one mean of assessment and coordination, but rather as part of a set of methods and procedures that can assess each individual in different ways.

Gorla et al. (2008) mentioning that individuals who have difficulty in movement, show a coordination disorder, often have problems associated with learning. Thus, the practice of physical activity from childhood and a daily exercise program, improve the expression level of coordination, contributing to the development of the individual and their quality of life (Barbosa et al., 2007; Lopes \& Maia, 1997). The present study found that compared to tests Battery $\mathrm{KTK}$, comparing G1 and G2, there was no significant difference in the ratios (QM1), (QM2) and (QM3), which differs from Malina et al. (2009) studies showing that individuals who are more advanced in maturational stages have mature movement patterns in a way that would influence the motor aspect. Though, the results of that study converge with Souza, Gorla, Araújo, Lifante \& Campana (2008) which notices that different factors can influence in those results, could mention the concentration difficulty, lack of attention in the moment of the task, impatience when they don't get to accomplish with success the movement and existence lack and experience in the proposed activities. Regarding the (QM4) - lateral transposition (TL), being possibly the most complex task and, for this reason, demanding a larger effort on the part of the performers during his/her realization. The task of transposing side is characterized by being a type of activity where the performer needs to combine speed and complexity, it must make use of all body segments and have under control action coordination to move from one platform to another. Comparing the results between the groups $G 1$ and G2, there was significant difference between the groups with the G2 demonstrated a better performance on the task. This result corroborates with the writings of Eckert (1993) when he says that the change in engine performance tends to correspond to changes in body size, strength and physiological functioning at puberty, which is observed in the group of girls after menarche.

Studies involving maturation have been considered, but few are those who find differences with respect to maturational stages. Thus, Lopes, Maia, Silva, Seabra, and Morais (2003) explain that most often occur differences in girls of a given age compared to results expected for their age group, individuals of the same age have diversified motor coordination or even below the standards expected. This is due to lack of physi- 
cal activity and insufficient work, because when it is established and monitored carefully it contributes significantly to learning, and it is satisfying and beneficial (Deus et al., 2008). Analyzing the maturational process and motor development, Ulbrich et al. (2007) clarify that further studies in this area should be developed to promote a better understanding.

Motor coordination is an important physical quality and dermatoglifia presents itself as one of the possible indicators of genetic predispositions coor- dinative and basic physical qualities. The association of those two variables can contribute in a profitable way to notice if there is a dichotomy between the development of the capacity coordinative and the genetic predisposition and, like this being, to subsidize an intervention so that this basic physical quality is added.

The motor tests that make up the protocol used in this study are related to the physical qualities of balance, agility, speed and coordination. Comparing

\section{TABLE 2}

Comparison results of dermatoglyphic characteristics between groups G1 and G2.

\begin{tabular}{rrrrr}
\hline \multicolumn{5}{c}{$M$} \\
\hline & A & \multicolumn{1}{c}{$\mathrm{L}$} & \multicolumn{1}{c}{ W } & D $(10)$ \\
\hline G1 & 22.90 & 25.17 & 20.76 & 21.29 \\
\hline G2 & 23.08 & 21.10 & 24.96 & 24.50 \\
\hline$p$ & .367 & .565 & .176 & .168 \\
\hline \multicolumn{6}{c}{}
\end{tabular}

Legend: A - Arch; L - Hook; W - Whorl; D(10) - Distal phalanges of 10 fingers; $M$ - Mean;

G1 - Group 1; G2 - Group 2; $\boldsymbol{p}$ - Probability.

\section{TABLE 3}

Comparison of the results of absolute power in the $a$ and $\beta$

(electroencephalographic features) between groups $G 1$ and $G 2$.

\begin{tabular}{cccc}
\hline \multirow{2}{*}{ Electrodes } & \multicolumn{2}{c}{$M$} & \multirow{2}{*}{$p$} \\
\cline { 2 - 3 } & G1 & G2 & \\
\hline F3A & 22.90 & 23.08 & .946 \\
\hline FZA & 21.86 & 24.00 & .585 \\
\hline F4A & 22.29 & 23.63 & .733 \\
\hline C3A & 25.48 & 20.83 & .237 \\
\hline CZA & 22.33 & 23.58 & .750 \\
\hline C4A & 25.33 & 20.96 & .265 \\
\hline P3A & 23.14 & 22.88 & .946 \\
\hline PZA & 23.67 & 22.42 & .750 \\
\hline P4A & 23.38 & 22.67 & .856 \\
\hline F3B & 25.67 & 20.75 & .219 \\
\hline FZB & 22.43 & 23.50 & .785 \\
\hline F4B & 24.00 & 22.13 & .633 \\
\hline C3B & 23.81 & 22.29 & .699 \\
\hline CZB & 22.48 & 23.46 & .802 \\
\hline C4B & 25.52 & 20.79 & .228 \\
\hline P3B & 23.14 & 22.88 & .946 \\
\hline PZB & 22.95 & 23.04 & .982 \\
\hline P4B & 24.14 & 22.00 & .585 \\
\hline
\end{tabular}

Legend: $\boldsymbol{M}$ - Mean; G1 - Group 1; G2 - Group 2; $\boldsymbol{p}$ - Probability. 
the results of this protocol with the dermatoglyphic patterns presented, we can conclude that, when it comes to speed and strength qualities that are valued in the physical test battery KTK, both groups showed satisfactory results. This result may have been influenced by the presence of larger D10 values of the two groups, as they are, according to Dantas \& Fernandes Filho (2002) in category III qualification sport.

The data obtained (Table 2), with respect to dermatoglyphic patterns, corroborate the studies of Klein (2003) that when comparing the relationship between dermatoglyphic, the physical qualities and maturity level of students of both sexes, also found no difference between dermatoglyphic patterns presented by women's groups prepubescent and pubescent. Overall, in this study, verification of genetic potential based on dermatoglyphic variables, showed no significant difference between the groups before and after menarche.

The age range of 7 to 11 years is characterized by major changes, both of a biological and psychological and social, which covers, among other things, the maturation of brain electrical activity (Gasser, Verleger, Bãcher, \& Sroka, 1988). With increasing age, the background activity of the EEG undergoes modifications, particularly for infants, pre-school age, but still variations to the end of adolescence (Ibid). According to these authors, there is a provision of maturation occurs subsequent to the above regions. Such fact is possible to observe in adolescents that present difficulties for the development of the executive functions, once the same ones possess the frontal lobe function such as manager (Gomes \& Bello, 2004).

The use of quantitative analysis of brain activity enables the quantification of data which, in a way, facilitates the understanding of the composition of the frequency of brain activity. This quantitative contribution is important, since the conventional EEG examination is based on visual reading the traces and is thus a subjective component (American Academy Neurology, 1997). Some measures can be used to obtain the EEG activity of brain rhythms. In this study we opted for the analysis of the absolute potency in order to if it compares, among the groups G1 and G2, the alterations of the rhythms alpha and beta, because to the if it accompanies the process of cerebral maturation in normal children it is known that, until the adult phase, it exists decrease of the activities theta and delta (slow) and increase of the activity alpha. This maturation process seems similar to studies conducted in different populations such as United States, Barbados and Cuba (Alvares, Valdes, \& Pascual, 1987).
Comparing the groups G1 and G2 regarding electric activity of alpha and beta (Table 3), it was not found significant difference. It understands each other that the age group among the groups is very close, which maybe, it can be a factor to explain such result. These results corroborate studies Fonseca et al. (2003) in analyzing "normal" individuals between 7 and 11 years, hwo also found no significant difference in the absolute power of alpha and beta. The alpha activity is common in individuals who are at rest, which also converges with the aforementioned study, because in both studies the spectral activity was also captured with the subjects awake and with eyes closed. In what it refers to the wave beta, EEG studies eletroencefalográficos have been presenting out of sync (ERD) processes and synchronization (ERS) in the rhyme of beta, a decrease and a ghastly increase of this rhythm, in function of motor events, could be observed in primary motive areas during the voluntary movement (Feige, Aertsen \& Feige-Kristeva, 2000) the mental planning of the movement (McFarland, 2003) and also during passive movements. (Alegre et al., 2002).

In this context, the results of this study support previous data from other studies, since there was no planning or mental and motor actions at the time of capture spectral activity, what has probably contributed so that oscillations in beta were not produced.

\section{Results of the association between the groups before and after menarche}

Studies involving maturation and motor coordination and dermatoglyphic patterns have been developed throughout the ages. However, when dealing with correlations between these variables and EEG, few studies have been developed. Then, with respect to maturation and motor coordination, according to the literature, performance should improve with age, and the best results, on average, found in older subjects (Malina \& Brown, 1998). However the data for this statement diverge from this study (Table 4), since we did not find a correlation between these profiles.

With respect to dermatoglyphic profile and motor coordination, this can make a correlation in the case of coordinative abilities, because studies like Assef, Oliveira, Teixeira, and Alonso (2009) to analyze the profile of the athletes of the Brazilian women's soccer under 17, found among the 45 athletes participating in the study, 23 women with high predisposition dermatoglyphic, ie, low incidence of the number of arcs, to obtain the best results on the test of motor coordination. 
Also related to the use of dermatoglyphic profile, the concomitant use of EEG, can quote the study Bogdanov, Gorbachevskaya, Solonichenko, Yakupova, and Iznak (1998) performed with 80 healthy girls, aged 6 to 8 years and with different dermatoglyphic patterns. Results found that the group with 10 loops $(\mathrm{L})$ at the fingertips $(n=18)$ correlates with a decrease in alpha spectral density, especially in the fronto-temporal compared to those without this pattern. In contrast, the group $(n=22)$ with the predominance of 8-10 whorls (W), the spectral density banda alpha was higher than in the other groups. With regard to the data of the present study, we can also observe an association between increased activity of alpha spectral (Table 4), but only the pair of front and center electrodes.

The alpha frequency band, in some studies, has been correlated with cognitive processes, with changes in light exposure of the subject to cognitive tasks with different levels of complexity (Angelakisa et al., 2004). However, in this study the subjects were not exposed to any task, just getting awake and with eyes closed, which is also a characteristic of increased spectral activity in alpha.
With the division of cases into groups, based on multivariate statistical Cluster, the case number 2, composed of girls aged 15 years, showed the significant difference, but only in electroencephalographic profile, especially in the rhythm alpha and frontal regions (electrodes F3, FZ, F4) and central (electrodes $\mathrm{C} 3$ and CZ) and Wilk's Lambda $F_{(2 ; 5029 ; 461)}=14.000$, $p=.001$.

Studies indicate that girls in older age have a different pace of spectral activity and these changes may be related to genetics, however, suffering from environmental influences. The EEG can be applied for optimization studies in neurophysiology, neurology and clinical psychiatry because this examination revealed peculiarities in children with different patterns dermatoglyphic corroborating the suggestion of Bogdanov et al. (1998) when it says that "the patterns dermatoglyphic can be correlated with individual characteristics of EEG and, possibly to serve as a marker of certain aspects of SNC".

The results related to the pace and beta corroborate the research that points like a beta rhythm related to planning and also the mental sensory-motor integration (Kandel, Schwartz, \& Jessel, 2003). The

\section{TABLE 4}

Results of the association among motor characteristics, dermatoglyphic and EEG absolute power - Alfa (A).

\begin{tabular}{lcl}
\hline \multicolumn{1}{c}{ Variables } & Case & $p$ \\
\hline QM1 (motor profile) & 2 & .340 \\
\hline QM2 (motor profile) & 2 & .213 \\
\hline QM3 (motor profile) & 2 & .216 \\
\hline QM4 (motor profile) & 2 & .077 \\
\hline A (dermatoglyphic profile) & 2 & .689 \\
\hline L (dermatoglyphic profile) & 2 & .770 \\
\hline W (dermatoglyphic profile) & 2 & .592 \\
\hline D10 (dermatoglyphic profile) & 2 & .445 \\
\hline F3A (electroencephalographic profile - Alfa) & 2 &. $\mathbf{0 0 1}$ \\
\hline FZA (electroencephalographic profile - Alfa) & 2 &. $\mathbf{0 0 0}$ \\
\hline F4A (electroencephalographic profile - Alfa) & 2 &. $\mathbf{0 0 1}$ \\
\hline C3A (electroencephalographic profile - Alfa) & 2 &. $\mathbf{0 0 4}$ \\
\hline CZA (electroencephalographic profile - Alfa) & 2 &. $\mathbf{. 0 0 3}$ \\
\hline C4A (electroencephalographic profile - Alfa) & 2 & .160 \\
\hline P3A (electroencephalographic profile - Alfa) & 2 & .100 \\
\hline PZA (electroencephalographic profile - Alfa) & 2 & .100 \\
\hline P4A (electroencephalographic profile - Alfa) & 2 & .190 \\
\hline
\end{tabular}

Legend: $M$ - Mean; G1 - Group 1; G2 - Group 2; $\boldsymbol{p}$ - Probability. 


\section{TABLE 5}

Results of the association among motor characteristics, dermatoglyphic and EEG absolute power - Beta (B).

\begin{tabular}{lcc}
\hline \multicolumn{1}{c}{ Variables } & Case & $p$ \\
\hline QM1 (motor profile) & 2 & .340 \\
\hline QM2 (motor profile) & 2 & .213 \\
\hline QM3 (motor profile) & 2 & .216 \\
\hline QM4 (motor profile) & 2 & .077 \\
\hline A (dermatoglyphic profile) & 2 & .689 \\
\hline L (dermatoglyphic profile) & 2 & .770 \\
\hline W (dermatoglyphic profile) & 2 & .592 \\
\hline D10 (dermatoglyphic profile) & 2 & .445 \\
\hline F3A (electroencephalographic profile - Beta) & 2 & .843 \\
\hline FZA (electroencephalographic profile - Beta) & 2 & .616 \\
\hline F4A (electroencephalographic profile - Beta) & 2 & .831 \\
\hline C3A (electroencephalographic profile - Beta) & 2 & .867 \\
\hline CZA (electroencephalographic profile - Beta) & 2 & .986 \\
\hline C4A (electroencephalographic profile - Beta) & 2 & .683 \\
\hline P3A (electroencephalographic profile - Beta) & 2 & .395 \\
\hline PZA (electroencephalographic profile - Beta) & 2 & .905 \\
\hline P4A (electroencephalographic profile - Beta) & 2 & .293 \\
\hline
\end{tabular}

Legend: $M$ - Mean; G1 - Group 1; G2 - Group 2; $p$ - Probability.

activity of the beta rhythm exhibits increased spectral amplitude as a function of engine events and also because the afferent when different stimuli are presented. Then, for there not being visual incentives and much less motors in the moment of the reception of the ghastly activity of both groups, generating synchronization in the rhythm beta, it justifies the found results (Table 5).

\section{CONCLUSION AND RECOMMENDATIONS}

From the results it was observed that, with respect to motor characteristics, dermatoglyphic and EEG, the groups are not presented separately. However, to join the motor characteristics, dermatoglyphic and EEG groups before and after menarche, there was a significant difference with respect to brain activity only in the alpha rhythm and at frontal (F3, FZ, F4) and central (C3 and $\mathrm{CZ}$ ) and in the post menarche (G2). Then, from these results, we can conclude that, with advancing age, the activity spectrum of the alpha rhythm tends to undergo changes both with respect to amplitude and also its distribution in the brain regions, since the predominance of its initial location is in the posterior region, more precisely in the oc- cipital lobe, showing that age is a determining factor in brain activity in girls before and after menarche.

Then, we are suggested other studies with larger samples and that present chronological age different from the biological age. Such characteristics, possibly, would point larger differences among the researched variables.

\section{REFERENCES}

Alegre, M., Labarga, A., Gurtubay, I. G., Iriarte, J., Malanda, A., \& Artieda, J. (2002). Beta ectroencephalograph changes durin passive movements: sensory afferences contribute to beta event-related desynchronization in humans. Neuroscience Letters, 331, 29-32. doi: 10.1016/ S0304-3940(02)00825-X

Alvares, A., Valdes, P., Pascual, R. (1987). EEG developmental equations confirmed of Cuba school children. Electroencephalogr Clin Neurophysiol, 67, 330-332. doi: 10.1016/00134694(87)90119-2

American Academy of Neurology and American Clinical Neurophysiology Society. (1997). Assessment of digital EEG, quantitative EEG and EEG brain mapping. Neurology, 49, $277-$ 
292. doi: 10.1212/WNL.49.1.277; Pmid: 15003770

Angelakisa, E., Lubarb, J. F., Stathoupouloua, S., \& Kouniosa, J. (2004). Peak alpha frequency: an electroencephalographic measure of cognitive preparedness. Clin Neurophysiol, 115, 887-897.

Assef, M., Oliveira, A. S., Teixeira, E. S., \& Alonso, L. (2009). Dermatoglifos como preditores da coordenação motora em atletas da seleção brasileira feminina de futebol sub-17

Dermatoglyphics as predictors of motor coordination in female athletes of the Brazilian national under-17 football]. Lecturas: Educacion Física y Deportes, 14(132), s/p.

Barbosa, E. L., Araújo Filho, M. A., Montenegro, R. C., Sousa, J. B., Montenegro, V. C. G., Dantas, P. M. S., \& Fernandes Filho, J. (2007). Maturação sexual: análises das medidas antropométricas e somatotípicas de escolares [Sexual maturation: analysis of anthropometric and somatotype of schoolchildren]. Fitness \& Performance, 1, 10-13.

Bogdanov, N. N., Gorbachevskaya, N. L., Solonichenko, V. G., Yakupova, L. P., \& Iznak, A. P. (1998). EEG mapping in children with different dermatoglyphic patterns. Brain Topography, 10(3), 221-225.

Collet, C., Folle, A., Pelozin, F., Botti, M., \& Nascimento, J. V. (2008). Nível de coordenação motora de escolares da rede estadual da cidade de Florianópolis [Level of coordination of schoolchildren of the state of the city of Florianópolis]. Motriz: Revista de Educação FísicaUNESP, 14(4), 373-380.

Conselho Nacional de Saúde. Normas para a realização de pesquisa em seres humanos, Resolução 196/96. (1996) [Standards for conducting research on human subjects, Resolution 196/96].

Dantas, P. M. S., \& Fernandes Filho, J. (2002). Identificação dos perfis genético, de aptidão física e somatotípico que caracterizam atletas masculinos, de alto rendimento, participantes do futsal adulto no Brasil [Identification of genetic profiles, fitness and somatotypical featuring male athletes, high performance, participants in adult indoor soccer in Brazill. Fitness e Performance Journal, 1(1), 28-36. doi: 10.3900/ fpj.1.1.28.p

Deus, R. B. C., Bustamante, A., Lopes, V. P., Seabra, A. F. T., Silva, R. M. G., \& Maia, J. A. R. (2008). Coordenação motora: estudo de tracking em crianças dos 6 aos 10 anos da Região Autônoma dos Açores, Portugal [Motor control: a study of tracking in children 6 to 10 years of the
Autonomous Region of the Azores, Portugal]. Revista Brasileira de Cineantropometria e Desempenho Humano, 3, 215-222.

Eckert, H. M. (1993). Desenvolvimento Motor [Motor Development]. São Paulo: Manole Ltda.

Feige, B., Aertsen, A., \& Feige-Kristeva, R. (2000). Dynamic synchronization between multiple cortical motor areas and muscle activity in phasic voluntary movements. Journal Phisiology, 5, 2622-2629.

Fernandes Filho, J., \& Roquetti Fernandes, P. (2010). Novas Tendências da Avaliaşão Física [New Trends of the Physical Evaluation]. ISBN: 9788590994619. Rio de Janeiro.

Fernandes Filho, J. (1997). Impressões dermatoglificas: marcas genéticas na seleção dos tipos de esporte e lutas (a exemplo de desportistas do Brasil) [Print dermatoglyphic: genetic markers in selecting types of sport and fights (such as athletes from Brazil)] Unpublished doctoral disserattion, VNIIFK, Moscou.

Fonseca Junior, S. J., Dantas, P. M. S., \& Fernandes Filho, J. (2009). Antropometria, composição corporal, somatotipo e qualidades físicas básicas em escolares nos períodos pré e pós menarca [Anthropometry, body composition, somatotype and basic physical qualities in students pre and post menarche]. Arquivos em Movimento, 5(1), 4559.

Fonseca, L. C., Tedrus, G. M. A. S., Martins, S. M. V., Gilbert, M. A. P., Antunes, T. A., \& Laloni, D. T. (2003). Eletroencefalograma quantitativa em escolares sadios [Quantitative electroencephalogram in healthy schoolchildren]. Arquivos de Neuropsiquiatria, 61(3-B), 796-801. doi: 10.1590/S0004282X2003000500018; PMid: 14595486

Gasser, T., Verleger, R., Bãcher, P., \& Sroka, L. (1988). Development of the EEG of schoolage children and adolescents: I. Analysis of band power. Electroencephalogr Clin Neurophysiol, 69, 91-99. doi: 10.1016/0013-4694(88)90204-0; doi: 10.1016/0013-4694(88)90205-2

Goda, Y., \& Stevens, C. (1996). Synaptic plasticity: The basis of particular types of learning. Current Biology, 6(4), 375-378. doi: 10.1016/S09609822(02)00499-2

Gomes, M. da M., \& Bello, H. (2004). Maturação cerebral e eletroencefalograma Brain maturation and electroencephalogram]. Revista Brasileira de Neurologia, 40(1), 5-13.

Gorla, J. I., Duarte, E., \& Montagner, P. C. (2008). Avaliação da coordenação motora de escolares 
da área urbana do Município de Umuarama - PR Brasil [Assessment of the motor coordination of students from the urban area of Umuarama - PR Brazil]. Revista Brasileira de Ciência e Movimento, 2, 57-65.

Jasper, H. (1958). The ten-twenty electrode system of international federation. EEG and Clin Neurophysiol, 10, 371-375.

Kandel, E. R., Schwartz, J. H., \& Jessel, T. M. (2003). Princípios da neurociência [Principles of Neuroscience]. 4a. ed. São Paulo: Manole.

Kiphard, E. J., \& Schilling, F. (1974). Körperkoordinationstest fürkinder, KTK. Weinheim: Beltz.

Linhares, R. V., Matta, M. O., Lima, J. R. P., Dantas, P. M. S., Costa, M. B., \& Fernandes Filho, J. (2009). Efeitos da maturação na composição corporal, nos dermatóglifos, no somatótipo e nas qualidades físicas básicas de adolescentes [Effects of aging on body composition, dermatoglyphics, somatotype and basic physical qualities of adolescents]. Arquivos Brasileiros de Endocrinologia e de Metabologia, 53(1), 47-54. doi: 10.1590/S0004-27302009000100008; PMid: 19347185

Lopes, V. P., Maia, J. R. A, Silva, R. G., Seabra, A., \& Morais, F. P. (2003). Estudo do nível de desenvolvimento da coordenação motora da população escolar (6 a 10 anos de idade) da Região Autônoma dos Açores [Study of the level of development of motor coordination of the school population (6-10 years old) of the Autonomous Region of the Azores]. Revista Portuguesa, 3(1), 147-160.

Lopes, V. P., \& Maia, J. A. R. (1997). Efeitos do ensino no desenvolvimento da capacidade de coordenação corporal em crianças de oito anos de idade [Effects of education in developing the capacity of body coordination in children eight years of age]. Revista Paulista de Educasaão Física, 1, 40-48.

Malina, R. M., Bouchard, C., \& Bar-Or, O. (2009). Crescimento, maturação e atividade física [Growth, maturation and physical activity]. São Paulo: Phorte.

Malina, R. M., \& Brown, E. W. (1998). Growth and maturation of football players: implications for selection in youth programs. Insight: The F. $A$. Coaches Assocation J, 2, 27-30.

McFarland, D. J., Miner, L. A., Vaughan, T. M., \& Wolpaw, J. R. (2003). Mu and beta rhythm topographies during motor imagery and actual movements. Brain Topografy, 3, 177-186.
Mendonça, C. P., \& Anjos, L. A. (2004). Aspectos das práticas alimentares e da atividade física como determinantes do crescimento do sobrepeso/obesidade no Brasil [Aspects of eating habits and physical activity as determinants of growth of overweight / obesity in Brazil]. Cadernos de Saúde Pública, 20(3), 698709. doi: 10.1590/S0102-311X2004000300006; PMid: 15263980

Mirwald, R. L., Baxter-Jones, A. D. G., Bailey, D. A., \& Beunen, G. P. (2002). An assessment of maturity from anthropometric measurements. Medicine \& Science in Sports \& Exercise, 34(4), 689-694. doi: 10.1097/00005768-20020400000020; PMid: 11932580

Oliveira, A. M. A. de, Cerqueira, E. M. M., Souza, J. S., \& Oliveira, A. C. de. (2003). Sobrepeso e obesidade infantil: influência de fatores biológicos e ambientais em Feira de Santana/BA [Childhood overweight and obesity: influence of biological and environmental factors in Feira de Santana / BA]. Arq. Bras. Endocrinol. Metab, 47(2), 144-150. doi: 10.1590/S000427302003000200006

Oliveira Junior, A. V. (1996). Estudo do comportamento do crescimento e da maturação sexual em suas relacõos com a estratificação social em alunos do Colégio Pedro II na cidade do Rio de Janeiro [Study of the behavior of growth and sexual maturity in their relations with the social stratification of students in Colegio Pedro II in the city of Rio de Janeiro]. Unpublished master thesis, Instituto de Educação Física e Desporto, Centro de Educação e Humanidades, UERJ, Rio de Janeiro.

Roquetti Fernandes, P. (2004). Estudo comparativo da Dermatoglifia, Somatotipia e do Consumo Máximo de Oxigênio dos Atletas da Seleção Brasileira de Futebol de Campo Portadores de Paralisia Cerebral e de Atletas Profissionais de Futebol de Campo não Portadores de Paralisia Cerebral [Comparative study of Dermatoglyphics, somatotype and High Oxygen Consumer Athlete of the Brazilian Football Field Bearers of Cerebral Palsy and Professional Athletes Football Field not Cerebral Palsy Patients]. Unpublished doctoral disseration, UFRN.

Sérgio, M. (2001). Motricidade Humana e Saúde [Human Motricity and Health]. Revista da Educação Física/UEM, 12(2), 129-138.

Silva, T. M. (2007). Desenvolvimento percepto motor como forma de intervenção em distúrbios psicomotores em pessoas com necessidades educativas especiais [Perceptual 
motor development as an intervention in psychomotor disturbances in people with special educational needs]. Lecturas: Educacion Física y Deportes, 107, s/p.

Souza, N. A., Gorla, J. I., Araújo, P. F., Lifante, S. M., \& Campana, M. B. (2008). Análise da coordenação motora de pessoas surdas [Analysis of the motor coordination of deaf people]. Arquivo de Ciências da Saúde, 3, 205-211.

Thomas, J. R., Nelson, J. K., \& Silverman, S. J. (2007). Métodos de pesquisa em atividade física [Research methods in physical activity]. Artmed: Porto Alegre.

Ulbrich, A. Z., Bozza, R., Machado, H. S., Vasconcelos, I. Q. A., Stabelini, A.,
Mascarenhas, L. P. G., \& Campos, W. (2007). Aptidão física em crianças e adolescentes de diferentes estágios maturacionais [Physical fitness in children and adolescents of different maturational stages]. Fitness \& Performance Journal, 5, 277-282.

Vidal, S. M., Bustamante, A., Lopes, V. P., Seabra, A., Silva, R. G., \& Maia, J. A. (2009). Construção de cartas centílicas da coordenação motora de crianças dos 6 aos 11 anos da Região Autônoma dos Açores, Portugal [Construction of letters centílicas motor coordination of children from 6 to 11 years of the Autonomous Region of the Azores, Portugal]. Revista Portuguesa de Ciências do Desporto, 1, 24-35.

Received: February 4, 2013 Revision received: Jun 11, 2013

Accepted: Jun 27, 2013

Correspondence to: Leticia Rocha Ecard, PhD

Darcy Vargas, 90/504 Itaperuna Rio de Janeiro Brazil

Phone: 00552281244134 E-mail: leticiaecard@gmail.com 